\title{
EDUCATION MOBILE APPLICATION CHEMISTRY FORM 4
}

\author{
ANIS ADILLAH MOHD SHAMSUL ${ }^{1}$, MOHAMMAD AIZAT BASIR ${ }^{2 *}$ AND UWAISULQARNI \\ M. OSMAN ${ }^{3}$
}

${ }^{1.2}$ Faculty of Ocean Engineering Technology and Informatics, Universiti Malaysia Terengganu, 21030 Kuala Nerus, Terengganu, Malaysia. ${ }^{3}$ Faculty of Science and Maritime Environment, Universiti Malaysia Terengganu, 21030 Kuala Nerus, Terengganu, Malaysia.

*Corresponding author: aizat@umt.edu.my

http://doi.org/10.46754/umtjur.2021.10.006

\begin{abstract}
Nowadays, people around the world are learning chemistry through various means and every student has a mobile phone to help them to connect to the Internet which is a treasure trove of educational material. An app available for mobile phones known as Chemistry Form 4 focuses on developing a student's knowledge of chemistry using smartphones as a platform has been developed for students in Malaysia. This mobile app was developed using Android Studio and Unity 2019.1 programs. The agile method was used to develop this project because of its flexibility with regards to its working process. Starting from planning of the problem statement, to the provision of solutions and objectives of this project, and the analysis of the requirements from client phase. To analyze this project, a few diagrams such as use case diagram, use-case description, activity diagram, sequence diagram, and class diagram were used. Thereafter, the designing phase kicked in that included the normalization of data, the development of entity relationship diagram, data dictionary and CRUD statement for the project. This project also focused on the students' needs from a chemistry app, which included preparation, presentation, practice and performance. Those functions include preparing and reading notes that can be updated by teachers. Students can also answer questions provided by teachers and view their results at the end of the sessions. Last but not least the students can view the atomic structures and chemical nature using an augmented reality (AR) model after the scanning cards provided by developers. Students can use the app to enhance their creativeness in getting to know atomic structures in this manner. Providing updated notes and questions with the aid of instructors will allow the students to benefit from the advanced know-how and chemistry expertise of the instructors. The mobile apps help students to improve their basic understanding of chemical processes and recognise the value of learning chemistry.
\end{abstract}

Keywords: Mobile app, chemistry, Form 4.

\section{Introduction}

Chemistry is a difficult subject both to learn and to teach at the secondary and tertiary levels in Malaysia. Most of Form 4 students will take extra classes and tuitions to learn chemistry since the subject is first introduced to them in Form 4 and this will be their introduction to chemistry in preparation for the Sijil Pelajaran Malaysia (SPM) exams, otherwise known as the Malaysian Certificate of Education exam, which is a national examination taken by all $5^{\text {th }}$ form secondary school students in the country.

Some students find it difficult to score well in chemistry due to the difficulties they face in learning the subject and students who enter
Matriculation College, will face an even tougher time as they have to deal with more advanced chemistry lessons.

However, students who really want to understand and eventually master chemistry especially now with the pandemic disrupting school learning, can download the chemistry app or learn chemistry through the various websites provided by the schools.

The Chemistry app for Form 4 is a good help for every Form 4 student. This system will allow students to learn at their own pace and many of them may even come to love the subject. By using this system, they also will get to know their level of understanding since there will be test 
provided to them after every chapter that they read. By providing acronyms, students also will be able to remember the composition, structure, properties, and interaction of matter easily. This subject is important for every student who wants a career as a doctor, chemical engineer, food technologist, geologist, pharmacist and forensic scientist. There are many other careers which need understanding in chemistry. This system will be convenient for every student from every grade due to the capabilities and function of this system.

Besides that, students also learn how to conduct experiments, hence in this system, we will provide video and steps to assist them on how to conduct the experiment. This system will be helpful towards Form 4 students. An advance system like this is very convenient for students nowadays.

\section{Related Works}

Developers can see how the existing system works and work up the features that give the users the most utility. With this research paper, the developer can apply the concepts discussed herein as a benchmark to develop and or improve the app.

Other versions of the app had basic functions for students to use such as the ability to make and read notes, answer quiz questions, and they also used different interface designs in order to attract the students' attention. In this app, new features are available that allow students to learn chemistry in innovative ways. New types of approaches are used to ensure that this app maintains its momentum and continues to provide good value to the students.

The five existing chemistry apps reviewed by this study as a benchmark for Form 4 Chemistry are Memory Booster SPM Chemistry, Chemistry Pro2019, Chemistry, Chemistry Advisor and Organic Chemistry Flashcards.

Table 1: Comparison of existing chemistry mobile application

\begin{tabular}{cccccc}
\hline Aspect & $\begin{array}{c}\text { Memory Booster } \\
\text { SPM Chemistry }\end{array}$ & $\begin{array}{c}\text { Chemistry } \\
\text { Pro2019 }\end{array}$ & Chemistry & $\begin{array}{c}\text { Chemistry } \\
\text { Advisor }\end{array}$ & $\begin{array}{c}\text { Organic Chemistry } \\
\text { Flashcards }\end{array}$ \\
\hline $\begin{array}{c}\text { Type of } \\
\text { system } \\
\text { Platform }\end{array}$ & Mobile application & $\begin{array}{c}\text { Mobile } \\
\text { application } \\
\text { IOS and } \\
\text { Android }\end{array}$ & $\begin{array}{c}\text { Mobile } \\
\text { application }\end{array}$ & $\begin{array}{c}\text { Mobile } \\
\text { application }\end{array}$ & Mobile application \\
Features & -Notes & -Notes & $\begin{array}{c}\text { IOS and } \\
\text { Android }\end{array}$ & IOS and Android \\
& -Notes & $\begin{array}{c}\text {-Quiz and } \\
\text { Answer }\end{array}$ & -Quiz and Answer \\
Database & MySL & MySQL & Firebase & MySQL & Firebase \\
access & Yes & Yes & Yes & Yes & Yes \\
\hline
\end{tabular}




\section{Methodology}

The Form 4 Chemistry software model uses an agile method. Figure 1 is the short illustrative explanation of the agile methodology.

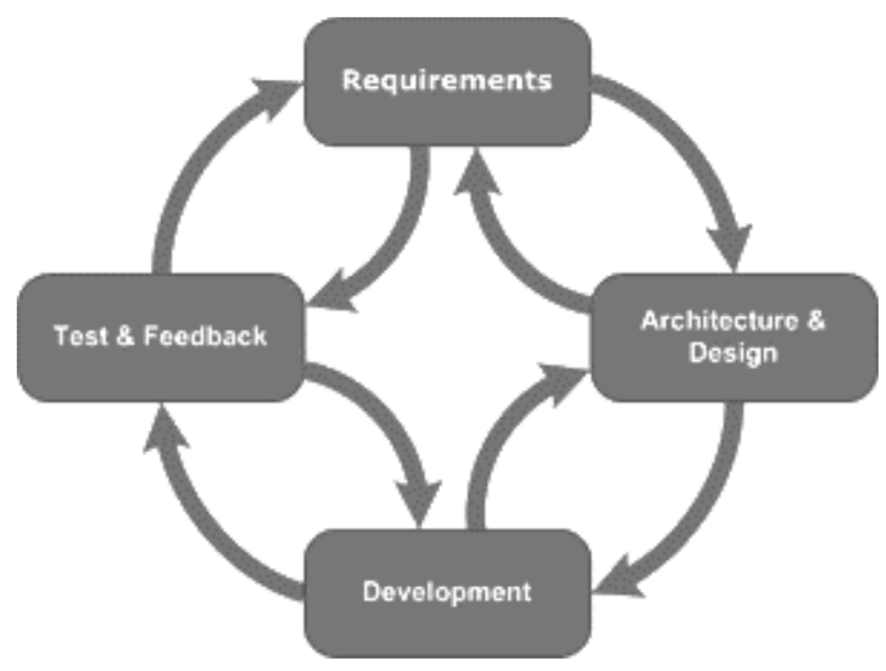

Figure 1: Agile methodology

The Agile model is one of the most used models in the software industry due to its flexibility in building a software project. The Agile model has six phases which are the planning phase, requirements analysis phase, design phase, coding phase, unit testing phase and the acceptance testing phase. This model was chosen because the project requirements are not set in stone, and the Agile method is more adaptable to changes in its requirements as the project develops. If users want to add any requirements during design phase, there would not be a problem.

After the design phase is the development phase. The agile methodology allows the design and development phase to be run simultaneously because users may want to change the design and see the results at the same time. Next is the acceptance testing phase where users can test the system.

Since the Chemistry app is being tested by the users and administrators at this stage, they can give feedback and the developer can use the feedback given to make changes directly as soon as it is given. This allows for all phases of the project to run concurrently and makes the agile methodology a very robust, cost-effective design platform.

\section{System Requirement}

The system requirements outlined in this study will explain the technical problems that were faced in the development of the mobile app. It covers:

- Ability

- Services provided;

- Expected outcome;

- Ensuring the specifications meet end-user requirements.

These are the functional requirements of the system:

\section{This system has a log in}

Users must be assigned with administrator privileges first before they able to use the application. Students and teachers can login to the app with assigned usernames and passwords 
given by administrator. This function is to add a security measure to the system.

\section{This system can display notes for students and teachers}

Users can view chemistry notes that were added by teachers. The notes provided is new information and can be updated from time to time by teachers.

\section{This system allows students to answer quizzes}

Students can answer quiz questions and view their scores after they answer all the questions in the module. The questions displayed follow the school; chemistry syllabus as approved by the Education Ministry.

\section{This system allows teachers to update quizzes and notes}

Teachers can enter questions and answers for students in the quiz module. The system will not display the same questions for students, drawing on the questions from a question bank at random. Teachers can also update the information in the notes module for students, to ensure the work is up-to-date.

\section{This system allows teachers and students to view the atomic structure of a chemical compound in Augmented Reality (AR)}

Teachers and students can view atomic structure of a chemical compound in AR after which they scan the smartcard provided by developer. This function can help them to depict what an atom looks like as a 3D model.

\section{This system allows the administrator to add, delete, replace or modify new users}

The Admin can enter new id and passwords for a new user. If a user wants to change his or her password, they must ask admin to change and update the id and password.

Table 2: Non-functional requirement of the system

\begin{tabular}{ll}
\hline i. Operational & The system will operate in android environment. \\
ii. Performance & $\begin{array}{l}\text { The system response time for every instruction conducted by the user will not } \\
\text { exceed more than a maximum of five seconds. }\end{array}$ \\
iii.Security & Only authorized students, teacher and staff can access to the mobile application. \\
iv. Usability & The system interface should be easy to use. \\
\hline
\end{tabular}

\section{System Analysis and Design}

A case diagram is used to describe the functional requirements of the system and the connections between the system and user. In this system, the users are students, teachers and the administrators. As the use-case diagram states, students are allowed to view notes, view atomic structures in augmented reality (AR) and answer quizzes provided by teachers.
Teachers are allowed to view notes, view atomic structures in AR and create questions for students.

The third class of user is the administrator is allowed to manage reports and notes for the system. Figure 2 shows the use case diagram for the Form 4 Chemistry mobile app. 


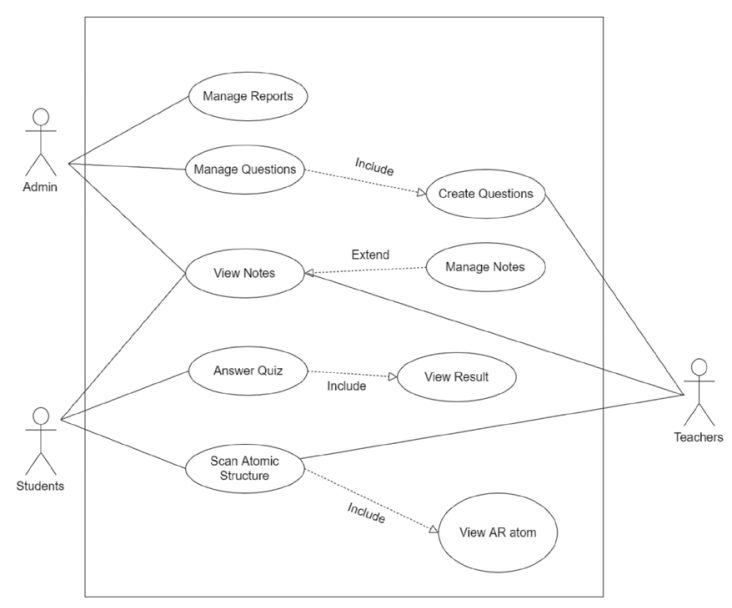

Figure 2: Overall system use case diagram

\section{System Implementation}

System implementation is the next phase, which happens after the Form 4 Chemistry mobile app is fully developed This system consists of three different user classes which are the students, teachers and administrators. Teachers and students need id authentication and passwords from the admin. After login, they may use the facilities in the app which are view notes, answer quizzes, update new information, update questions and the view atomic structure via AR.
Users do not need to login after they close the application. If a user uninstalls the application, they will need to login again with the id and password as they did before. This application is useful for teachers and students to communicate during online class.

Figure 3 shows the login interface for students, teachers and the admin. Users will receive specific ID's as their account passwords that is non-editable. Figure 4 shows the welcome page which appears upon a successful login.

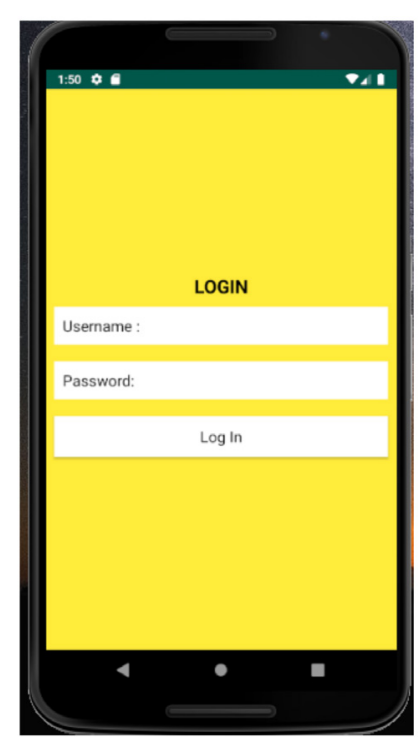

Figure 3: Login interface 


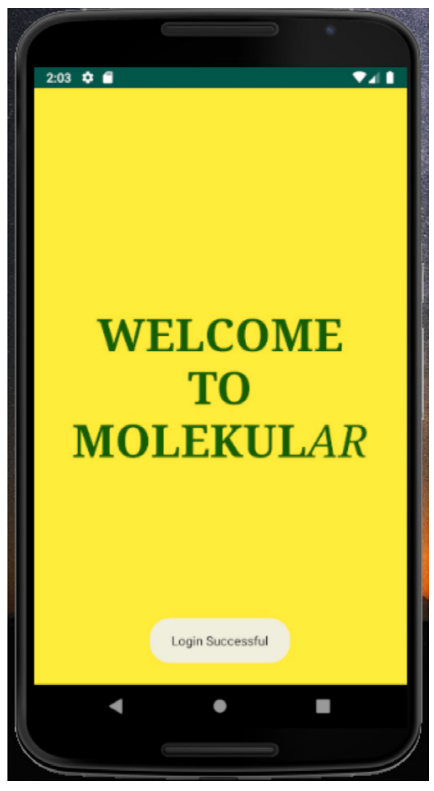

Figure 4: Welcome page

Figure 5 shows the menu for students and Augmented Reality (AR). Students and teachers teachers that consist of few choices such as will view this menu after they login into the app. view notes, quiz or scan atom to view atoms in

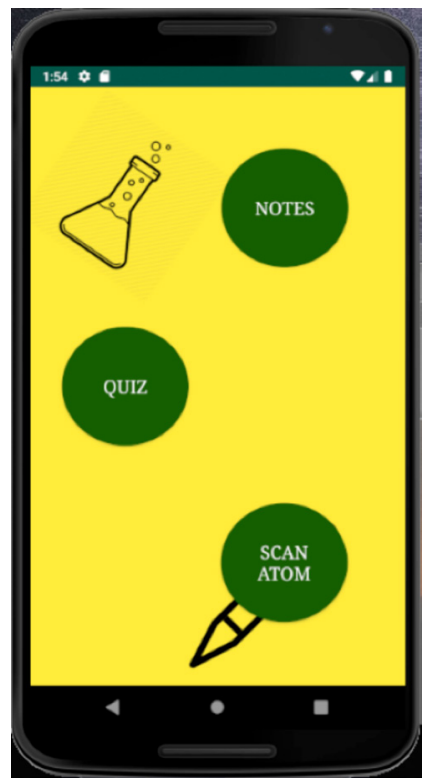

Figure 5: Menu for students and teachers 
Figure 6 is topics of notes that will appear when students and teachers choose notes on previous interface which is the menu. There are five topics provided in this app and all of them are related to the atomic structure model theory. The topics are John Dalton's theory, Thomson's theory, Chadwick's theory, Bohr's theory and Rutherford's theory.

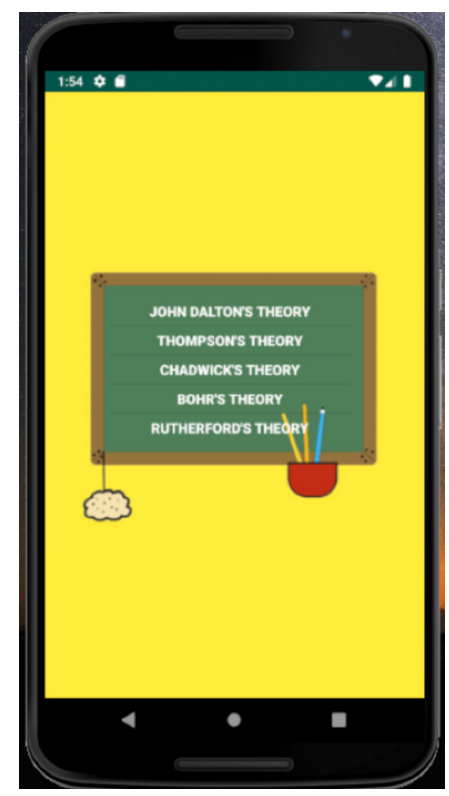

Figure 6: Topics of notes

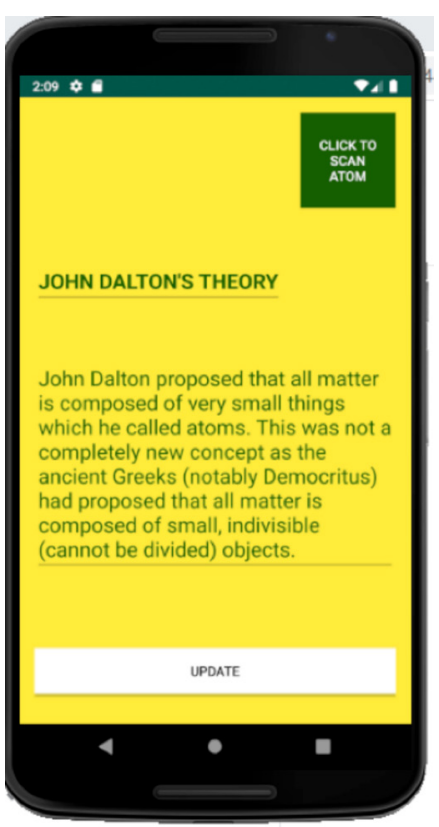

Figure 7: Interface design for teacher to edit note 


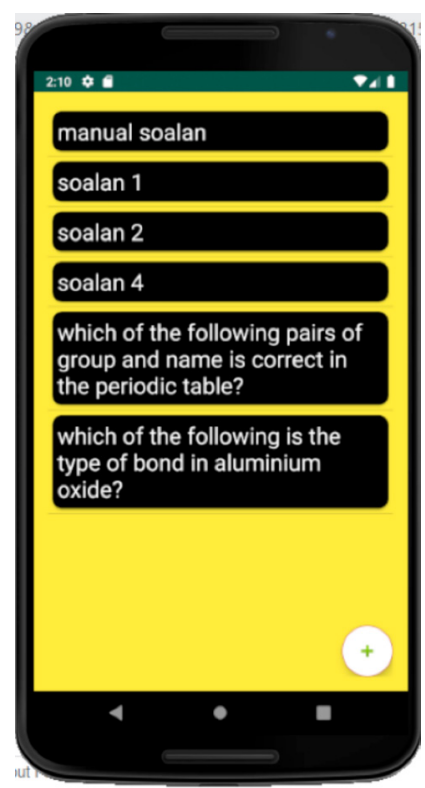

Figure 8: Questions bank module

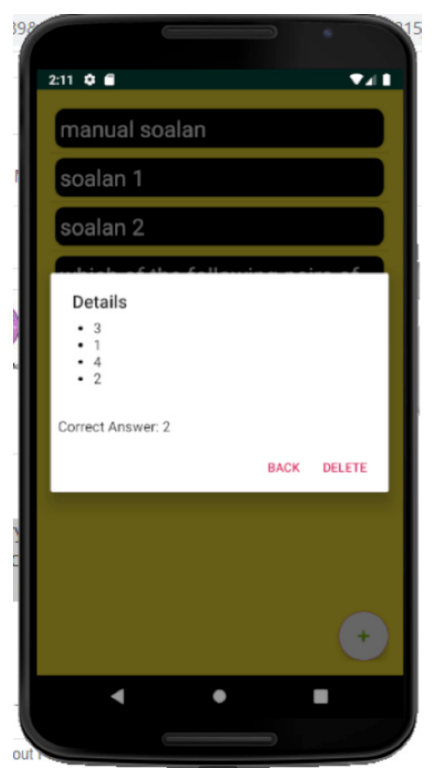

Figure 9: Deleting questions from the app (for teachers only) 
Figure 10 shows the interface design for teachers to create questions. Teachers must insert the multiple-choice questions and provide answers for the questions where there is only one right answer among the choices presented to the students. The students can only select one answer.

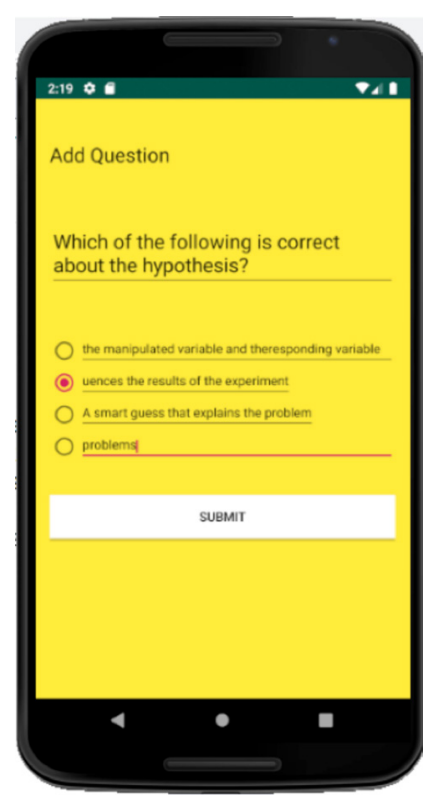

Figure 10: Interface design for teachers to create questions

Figure 11 is design for notes interface used atoms or go back to the "home" page by just by students. Students can view notes and scan clicking back button.

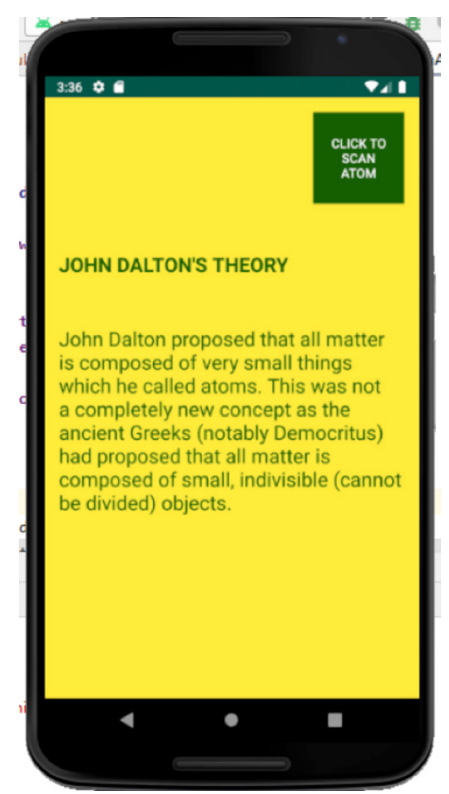

Figure 11: Note's interface 
Figure 12 shows the questions module for students when students want to answer questions.

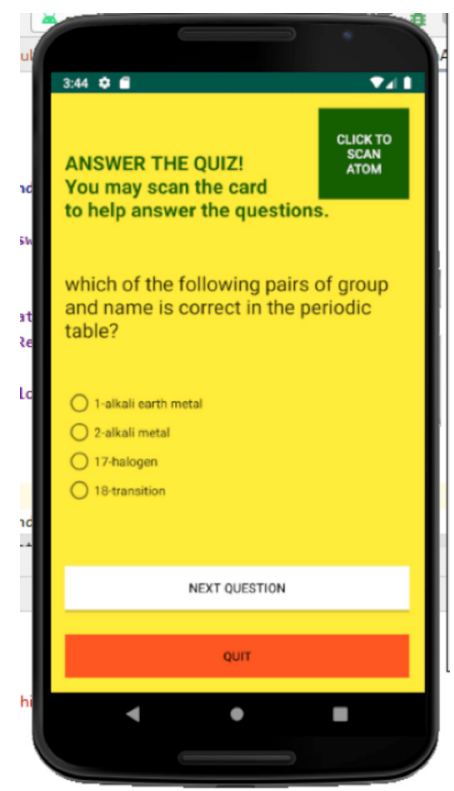

Figure 12: Question module

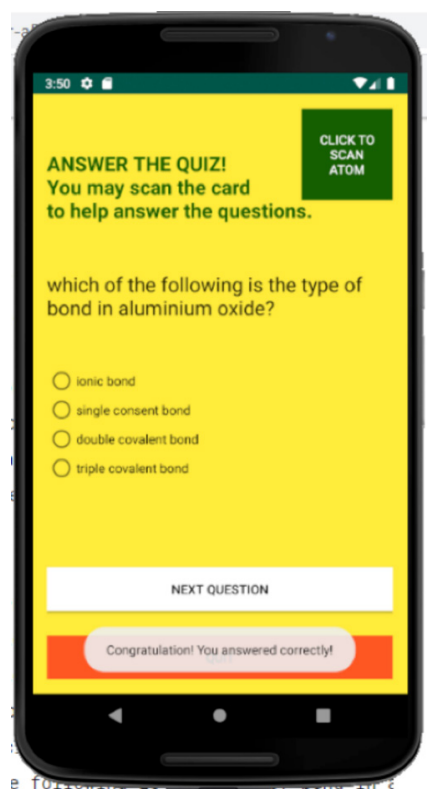

Figure 13: The interface when students answer the questions correctly 


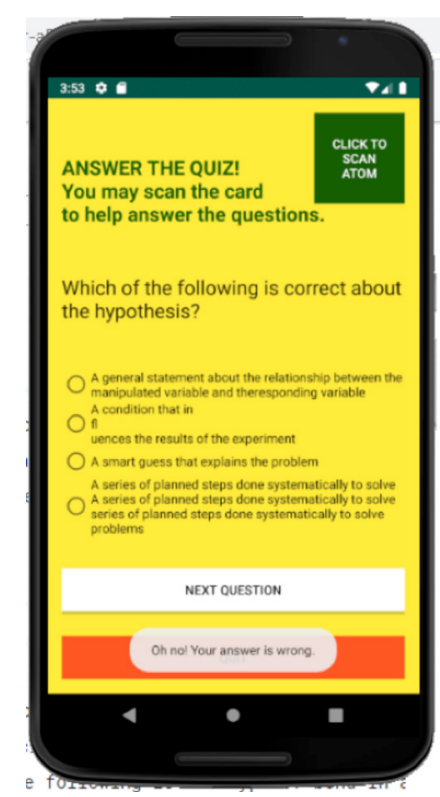

Figure 14: Interface when students select the wrong answer

Figure 15 reveals the marks from the quiz quiz questions, the system will show them a answered by students. After they answer all the tally of their scores.

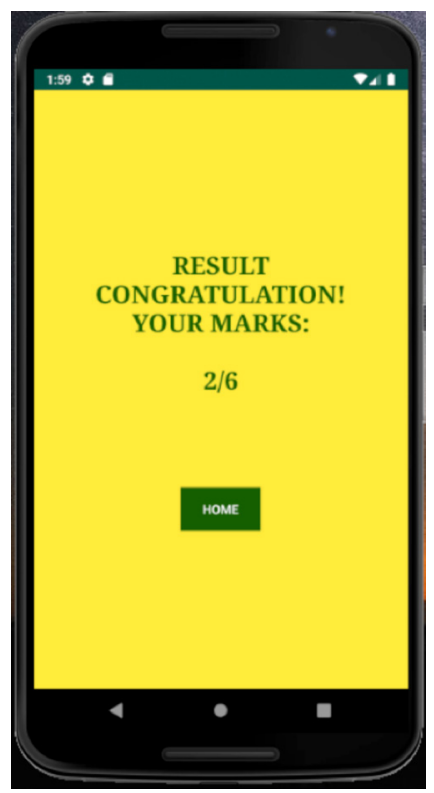

Figure 15: Marks 


\section{Conclusion}

Every app is evaluated according to their non-functionality requirement. The better the performance, security, usability, and correctness of the data the more efficient the app will be. An overview of the developed system is provided in this chapter.

The Form 4 Chemistry mobile app is developed for students, teachers, and administrators to use their smartphones to help them improve a students' knowledge of chemistry. This system can boost a student's insights on the atomic structures in their syllabus, while teachers can give them exercises to help them better understand the syllabus. Less effort is needed in learning chemistry since this app can be accessed via smartphones anywhere and anytime, without the need to carry heavy books. This system is very effective in assisting students with knowledge development. Every exercise provided by teachers will randomized to ensure that students do not answer the same questions repeatedly. Other than that, new information will be added from time-to-time for students to view.

There are several limitations that developer needed to analyze in the development of this system. To ensure user satisfaction, developer used Firebase to design it in real time and provide internet access users. The user interface is not interesting but uses appropriate colours for corporate websites.

Its limitations need to be improved. Improvement is a particularly important element in a system development life-cycle. The suggestion for first improvement is in user profile interface in this system. Finally, it is hoped that this system can help users learn chemistry in a more systematic and effective manner.

\section{Acknowledgements}

First and foremost, praise Allah SWT for the opportunity given in order for me to finish this project within the given time. Along my system development, I would like to thank everyone who helped me on this journey making it as easy as it can be and helping me acquire new knowledge. I want to sincerely thank Mr. Mohammad Aizat and Dr. Uwaisulqarni for always being there and providing guidance for the completion of this article. Thank you for the opinions that helped me learn new things.

I am also very grateful and indebted to my friends especially my best friend, Amirul Syafik Adlin who always encouraged me to complete this article on time last but not least, I would really like to express my gratitude to my family for their support and love.

\section{References}

Altexsoft, Functional and Nonfunctional Requirements: Specification and Types. (2018, May 29).

Carnegie Mellon University. (2017, December). Software Architecture. https://www.sei.cmu. edu/research capabilities/allwork/display. cfm?customel_datapageid_4050 $=21328$

Elgabry, O. (2017, March 18). Software Engineering - Software Process and Software Process Models (Part 2). https://medium.com/omarelgabrys-blog/ software-engineering-software-processand-software-process-models-part-24a9d06213fdc

https://www.altexsoft.com/blog/business/ functional-and-non-functionalrequirements specification-and-types/

Inflectra - What are System Requirements Specifications/Software (SRS)?. (2018, March) https://www.inflectra.com/ideas/ topic/requirements-definition.aspx.

Interactions design foundation. (2018) Usability https://www.interaction-design. org/literature/topics/usability.

J Report. (2019, January). 3- Tier Architecture: A Complete Overview. https://www. jinfonet.com/resources/bi-defined/3-tierarchitecture-complete-overview/ . 